$\xi=-1$

\title{
Coping experiences of Pakistani nurses against corona stressor; a qualitative study
}

\author{
Ali. H. Haider * \\ Bahria University Islamabad, Pakistan \\ *Corresponding author E-mail: psychobreath@gmail.com
}

\begin{abstract}
Objective: The aim of the present qualitative study was to find out how Pakistani Nurses are experiencing the coping strategies against Corona- Stressor.

Background: Corona is the World- Wide stressor for Nurses. The Pakistani Nurses are experiencing this stressor and are coping with it too. The present study is on Coping of Nurses of Pakistan against Corona- Stressor.

Method: Narrative variation of qualitative research with conventional content analysis was applied to extract results from open- ended interview questions which were administered on nurses face to face with purposive sampling technique.

Results: Six major themes; five of conventional coping strategies and one new coping strategy were used by Nurses against CoronaStressor.

Discussion \& Conclusion: Nurses in Pakistan are using Standard Operating Procedures as a new coping strategy against Corona Stressor with the already established conventional coping strategies.
\end{abstract}

Keywords: Content- Analysis; Coping; Corona- Stressor; Experiences; Pakistani Nurses.

\section{Introduction}

Report of Health System Strengthening Program in Pakistan indicates the training program in which the first 200 Nurses of Pakistan are going to get training to provide cure to Corona- Patients $(50+\mathrm{k}$ cases have been detected in Pakistan with $1.5 \mathrm{k}+$ deaths till now according to the official website of National Health Service Regulation and Coordination "NHSRC" Pakistan). This was mentioned in a report of United Nations Population Fund which was published in April 16, 2020. The stress that was limited only to real life stressors, job stressor and disease stressor, now has been extended to Corona- Stressor World- Wide and in Pakistan. The Nurses who were special victim of stress may now be considered as Corona- Stressed. The first case of Corona in Pakistan was reported after 20th February- 2020 and still the nurses are expecting any case anytime in Isolation wards of Hospitals. Nurses are primary caretakers in Health system for every country of the world and they are fighting on the front lines against Corona and the most important thing is that they should be kept away from this stressor so, they may focus on their primary job with full dedication and attention but unfortunately, almost in all countries of the world (including Pakistan), they are having a direct contact with the Corona- Patients either with or without the safety equipment. This direct contact is leading them to various sorts of mental disorders such as depression, anxiety and stress more than ever before. Regarding this issue, to my knowledge, no qualitative studies (even few quantitative studies) have been published from Pakistan so far. The current Study was concerned about Pakistani Nurses in the Isolation wards attending the Corona- Patients that either they were using enough coping mechanisms as the strategies to fight against Corona stressor or not. Also, it was a point of concern to know what kind of and how many coping strategies Nurses are using against Corona- Stressors.

The zero patient for Corona was found in Wuhan, China in 2019 and was supposed to be a deadly form of simple Pneumonia named as Acute Respiratory Syndrome Corona- Virus2.For the present qualitative study, the stressor for Nurses has been termed as CoronaStressor as the definition of stress for Nurses in hospital environment is to get exhausted by using all the available body energy in providing help to the patients (Corona- Patients in this case) and these patients are bringing the limit of exhaustion to nurses so, that's the reason that nurses are prone to corona stressor in the intense hospital environment (Isolation- Wards in this case) worldwide (Burti \& Mazzi, 2004; Hawthorne et al., 2009; Rossberg et al., 2008; Brunt \& Hansson, 2002; Johansson et al., 2013).

The present study filled actually the large gap of the internal hidden conditions of nurses in Pakistan who were coping against CoronaStressor by attending the patients and the mechanism of their coping was unknown to the world, even the data about their patients was not present in any research paper from Pakistan.

The previous ways of coping found I $n$ the literature given by Folkman \& Lazarus in 1988 are Confronting coping, Distancing, Selfcontrolling, Seeking Social Support, Accepting Responsibility, Escape- Avoidance, Planned Problem solving and positive reappraisal. These are so clear coping mechanisms that all of them are used by nurses of Corona- Patients in Pakistan and world- wide except the coping mechanism of distancing. 
A little is known about the perceived stress trends in Pakistani Nurses. Nurses who are not of much age experience more talking to their patients, staff and their physicians and that makes them at ease rapidly under stress conditions. They show less sympathy than older nurses but still enough that makes their patients happy with them (McLaughlin, 1994; Samuelsson, 1997). The caregivers for the psychiatric patients in Pakistani hospitals are mostly nurses and their large population goes through mental disorders frequently with stress. If the nurses provide a better care for the patients they attend, the wellbeing of their patients is likely to increase and if the quality of the care is not up to the significantly satisfactory level, then the patients may cause a dangerous level of stress for their caregivers and nurses and this stress may affect the working capabilities of their caregivers or nurses (Tabassum et al., 2014).

Corona patients are also a cause of stress for the nurses of Pakistan in isolation wards of the hospital. The coping mechanisms they are experiencing against the stress the Corona- Patients are producing for them are the main theme of this study. It is a qualitative study so, the epistemological location for an instrumental case study with a realist's point of view may be expected to happen anywhere in the study.

\section{Method}

Study Design: The narrative variation of conventional content analysis was used as a study design.

Sample: The sample $N=9$ ( $n=7$ females and $n=2$ male nurses) of Corona patients from two most trusted hospitals of Islamabad and Rawalpindi was taken.

Inclusion and Exclusion Criteria: Nurses of Corona Patients from Isolation wards having Master's degree with special diploma in Nursing were taken and no other nurses from any other ward of hospital were approached.

Data Collection: Open- ended and unstructured interviews with nurses of Corona- Patients were held by the researcher himself for the data collection for the present study outside of the isolation wards in the silent corners of the hospital. All the questions were about the core inquiries of coping experiences of nurses against the corona- stressor. Some of those questions were like;

How did you confront the Corona- stress when the Corona patient was first brought to you or was assigned under your duty for the first time?

How did you maintain a proposed distancing from Corona Patients while providing care to them?

How did you control yourself from being stressed while providing care to your Corona- patient?

How did you manage to calm down the proposed caregivers (only 1 in the case of Corona- Patient officially allowed to be quarantined with Corona patient while maintaining a safe a distance; the wife, son or primary relative was allowed for this purpose) of Corona patient? The interviews were conducted during the period of 1st of March to 22nd of May, 2020. Till the rich data was obtained, the interview was carried on in form of written files of answer- sheets as the video- audio recording was banned in the hospitals. .

\subsection{Analysis of data}

The conventional content analysis was used to analyse the data that is a modern form of technique to analyse qualitative thematic data by transcribing the data into main categories of a qualitative "Framework" (the data analysis method proposed by Bryman \& Burgess in 2002). Framework consists of five major steps that are thematic. To be familiarized with data, Framework identification, Data Indexing, placing data in charts, and devising maps of data and interpreting those maps into simple meanings. Firstly, transcribed verbatim of thee data was read and re- read to be familiarized with the true content of the data; Secondly, the data was categorized manually for easily identifiable types and streams of data; Thirdly, the written files of the free answers were shuffled and indexed in their right categories for which they belonged to; Fourthly, making the five clear headings under a chart to explore all the five themes in distinct points and Fifthly, the map of data was devised and interpreted accordingly by compare and contrast techniques (comparing one file's data with each other to find out the differences of answers of the patients) and trying to explain and describe reasons behind these found differences of opinions in participant's answers in thematic patterns and joining the consistent links between the themes.

\subsection{Exclusion of researcher's bias}

The researcher's bias was tried to be avoided by self- scepticism of the researcher and by proposing a self- assigned idea about being indifferent for what the nurses had provided in form of data and by making assumptions of going with what data exposed, considering the data themes ahead instead of researcher's own thoughts, doing research only for the purpose of extracting the experiences of coping methods of nurses against Corona stressor and conducting the interview of the participants with all possible true considerations, keeping in mind about the ample flexibility of all sorts to the present topic and to put the data into the most relevant categorical theme were all the steps taken by the researcher to make the data trustworthy, valid and transparent (Lincoln \& Guba, 1985).

\subsection{Ethical considerations}

All the ethical considerations were applied to the present study that is taking consent from the nurses to participate in the research, assuring for the anonymity and confidentiality about not leaking their given responses at any cost to any one, taking written approvals from the MS's of the hospitals to interview nurses and maintaining all sorts of possibilities of self - harm or harm to the participants away from the study. It was a voluntarily research and all the participants were told this before taking any interview.

\section{Results}

The sample of $\mathrm{N}=9$ nurses ( $\mathrm{n}=7$ females, $\mathrm{n}=2$ males) with mean age 29 and Standard deviation $(\mathrm{SD}= \pm 7), 5$ married and 4 singles and all having a master's degree with special (advanced) diploma in nursing were taken as the participants for the study. Nurses used CoronaCoping against Corona- Stressor carefully and effectively in six major categorical thematic- coping mechanisms by using Conventional (Folkman \& Lazarus. 1988) and new Corona- Coping style of Standard Operating Procedures.

Table 1: Demographic Properties of Sample

$\begin{array}{lc}\text { Variables } & \text { Number }(\%)\end{array}$

Age (Distribution Wise 


$\begin{array}{lc}22-29 & 3(33.33 \%) \\ 30-36 & 6(66.66 \%) \\ \text { Work Experience } & 2(23.23 \%) \\ 1 \text { - } 5 & 7(77.77 \%) \\ 5-10 & \\ \text { Employment Ward } & 9(100 \%) \\ \text { Isolation Ward } & 0 \\ \text { Other Wards } & 5(55.55 \%) \\ \text { Marital Status } & 4(44.45 \%) \\ \text { Married } & 45 \% \\ \text { Un- Married } & 7(77.77 \%) \\ \text { Gender } & 2(23.23 \%) \\ \text { Female } & \mathrm{N}=9 \\ \text { Male } & \end{array}$

\subsection{Controlling patient's initial situation}

Participant 2 wrote in the answer file, "we are always ready to control any situation either its general or is specific about any patient. We prepare an invoice first to send that suspected patient to the Corona- test portion and if the physicians ask us to place that patient in the isolation ward and assign us a duty on that patient for 24/ 7, we aide by the rules, so our half stress due to corona stressor dies there on the spot". This theme indicates that nurses in Pakistan are trained and concerned about the patient and remain always ready to cope with any situation that arises in the isolation ward of the Corona- patient.

\subsection{Providing help}

The participant Number 7 stated, "we are active and mean at the same time to do our duty first by providing help to our Corona- patients and we are mean in a positive way because we are married, we have kids and we think that no one should feed our kids except us and we consider our patients like our own kids or like our own elders in the case when they are our patients but we are truly worried when we find a minimum distance between us and our patients because we know it's a disease that can be ours anytime. We think, before a nurse provides care to us, we should provide cure to our patients to do our duty well. Then, we get a relief from Corona-stress with this thought". This theme indicates that the nurses of the Corona- patients cope with the situation by providing cure to their patients. The more help they provide to their patients, the more they think they are performing their moral duty and this type of thinking becomes a coping mechanism for them from Corona-Stressor. At the same time, somewhere deep down in the heart they may have a fear of getting Corona from their own patients and they want to keep the distancing too from their patients.

\subsection{Controlling self}

The participant Number 1 wrote, "We are in a total control of ourselves except for the time of sleep hours. After all; we are human beings'. The participant number 3 wrote, "We as nurses are well aware of our patients and we also are well informed by our doctors what to do in a situation and how to give medicine to our patient and how to inject them by right syringes because its our occupation to attend the patient carefully when we are in isolation wards". This theme indicates that the coping against corona stressor is at an optimum level in Pakistani nurses and the reason might for this type of coping be the extra knowledge and control of the needs of their patients.

\subsection{Sympathizing and soothing the patients}

The participant number 8 wrote, "We don't escape from the situation after we are assigned with the duty to be a nurse for a patient with corona. We lull our patients about the time being that is passing and tell them that this time will also not stop and we also tell our patients that this pandemic is not only for you an exam but for us too. We both shall go through this exam with effort to live and with courage". The thematic interpretation revealed that the nurses use great coping strategies against Corona- Stressor in terms of seeking support or giving support whenever needed to their patients by sympathizing to them and by making a firm decision to not escape from the pandemic stressor.

\subsection{Spiritual coping for self and for corona patients}

The participant Number 5 wrote, "As a Muslim, I feel that the impact of listening to morning recitation of the holy- Quran and performing Salah Prayers (Religious rituals) fills the mind up with a calming and contended effect on heart and mind of three of us i.e. me, the allowed family caregiver and my patient going through Corona". The theme indicates that a strong religious faith leads nurses of Corona patients in Pakistan to a coping strategy that is termed as spiritual coping and it only is experienced when there is a religious faith on Allah Almighty or God.

\subsection{The corona- coping}

This was the exclusive coping strategy that is not the part of conventional coping styles and may be for the first time in any Pakistani study is mentioned. The present study is going to propose this term Corona- coping and this type of coping surely may not be supported by the previous literature of studies because, before this pandemic, there was no such coping existed in the world. The key result of theme was that nurses used Standard Operating Procedures (SOP's) as a coping mechanism against corona stressor and these SOP's are

- Washing hands

- Use of Face Mask

- Sanitizer usage

- Distancing of at least 2- feet from the Corona- Patient

- Using Gloves. 
- Using Dress- Kit against Corona

- Keeping distance even from the caregiver of the patient in Isolation Wards.

The participant Number 3 wrote, "We are using standard Operating Procedures extensively and its for the first time that neither the allowed caregiver, nor the Corona- patient is stopping us from our odd behaviours".

Graphs and other numbered figures should appear throughout the text as close to their mention as possible. Figures shouldn't infringe upon the page borders.

Figures and tables must be cantered in the column. Large figures and table can be in one column in order to see them more clearly and avoid placing them in the middle of columns. Any table or figure that takes up more than 1 column width must be positioned either at the top or at the bottom of the page

Photos must be crystal clear with such resolution to allow fine details visibility. The elements from any photo must be explained using numbers, letters, etc. The text within a figure or photo must have the same style, shape and height as the caption has.

Any table, figure or picture must have a caption (Fig.1, Table1, etc.) followed by a proper description. All similar graphics must be generated using the same software product (Excel, Origin, Mathematica, etc.). Importing graphics into the article as images (JPG, BMP, PNG, etc.) should be avoided. All similar electronic schematics, charts, program flow, simulated characteristics, etc. from the article should be generated using the same software product. Importing images from other articles or books it's totally forbidden unless they are cited.

\section{Discussion}

The findings of the present study are less supported by the other studies which are mostly quantitative and have scales- based results but still in various ways the findings of this study are supported by a few qualitative studies.

Nurses use coping mechanism of Controlling Patient's Initial Situation in almost all the cases where they look smart, intelligent and over efficient to control each and every situation of the newly admitted patient; no matter that patient may be of Corona (Loo \& Beh, 2011). The mentioned study supported the idea that nurses use this type of coping against Corona- stressor by controlling all the situations of Corona because in the result of that study, it is mentioned that $63 \%$ of nurses do so in all cases when they get into contact with any other patient of any other disease.

The coping mechanism of providing help in quick time at the right spot to the Corona- patients by nurses is supported by the control demand model which states, "The patient has any demands, the nurses control it to stay away from any stress". The model proposed by Karasek (Karimi et al., 2011). So, it might be thought that whenever the Corona patients need something, the nurses might have been there to provide the help. The simple formula "to help the patient" is the way to stay away from Corona Stressor.

Controlling self, turned out to be a strong coping mechanism in Nurses of Corona patients in Pakistan according to the present study and the notion or narration of the fact was supported by the literature as the nurses have a mechanism to control themselves in stressed situations and to do the right things in response to the perceived stressful situations in advance (Folkman et al., 2004; Greenglass, 2002).

The result of the study that nurses use a stress- coping mechanism of sympathizing and soothing the caregivers is also supported by the literature that indicated the similar results in some studies. The result that fully supports is of the study conducted by chang and Co- authors in 2006 and another study conducted by Loo and Co- authors in 2012 and both the studies indicated the nurses use a coping mechanism of seeking social support and giving it in return. The nurses of the present study gave social support to the caregivers and their Corona- patients probably for the un- conscious desire of having that support back to them from the Corona- patients and their family caregivers.

The coping strategy used by the nurses emerging in the results of this study also has been spiritual coping for self and for their Coronapatients and the literature also supports this result as humor words, meditation practices, accepting the power of Almighty Allah/ God are some common spiritual practices nurses in many hospitals and nurses of many patients going through crucial stages of their diseases do (Jannati, 2011; Harris, 2013; Bakibinga, 2014).

No supportive data was found for Corona coping as it is solely the term emerged from the present study and no past qualitative or quantitative studies support or reject this coping mechanism but the present study supports this Coping Style to the optimal level for Pakistani Nurses of Corona- patients.

4.1. Limitations of the study:

Researchers are the instruments of the qualitative studies themselves so no conventional instrument like SPSS or EMOS etc. were used in this qualitative study but all the results were manually transcribed verbatim into themes. Self- scepticism was the only method to avoid researcher's bias in the study and social desirability bias of participants was controlled by selecting only the nurses of Corona- patients who were in isolation wards with the patients who were inly in the initial stages of Corona by their hospital reports. The minor limitation includes shortage of time, dropping down the sample number due to last- minute withdrawal of the participant of the study and strict limitations of keeping the data confidential and private.

\section{Conclusion}

The coping strategies emerged from the present study used by the nurses for stress coping against Corona stressor are the need of the hour. These strategies are supported by the literature, by many quantitative studies, few qualitative studies and thoroughly by the primitive coping theories proposed by the researchers and philosophers of the past, so, these strategies may turn into an essential practice or might be taught to the nurses in their academic curriculum. The findings of the present studies must be proposed in a form of a bill in the parliament of the Pakistan so the government may include these coping strategies in the up- coming syllabus of nursing in Pakistan and also may include them into the code of conducts of the Pakistani hospitals as the Standard- Operating Procedures are already in code- of - conduct of the Pakistani Hospitals. The future studies may be conducted in the topic that either the nurses perform these coping styles knowingly or on un- conscious level. 


\section{Acknowledgement}

I am thankful to the participants (Nurses) who made this study possible at one condition that I shall not reveal their data or name but only in anonymity wherever needed in the paper. I am thankful to the MS's of Hospitals who permitted me to access my sample population. I am thankful to my dear teacher Dr. Uzma Masroor for all Special Reasons (making me able to conduct the studies on my own).

\section{References}

[1] Abraham, M. (2017). A Phenomenological Inquiry of Nurses' Lived Experiences of Implementing Evidence in Practice.

[2] Beh, L. S. (2011). State Legitimacy and Implementation of a Public policy in Malaysia. International Journal of Policy Studies, 2(1), 27-42.

[3] Brunt, D., \& Hansson, L. (2002). Characteristics of the social environment of small group homes for individuals with severe mental illness. Nordic Journal of Psychiatry, 56(1), 39-46. https://doi.org/10.1080/08039480252803909.

[4] Burti, L., Andreone, N., \& Mazzi, M. (2004). Reassessing treatment environments after two decades: client and staff perceptions of an Italian community mental health service environment, then and now. Community mental health journal, 40(3), 199-210. https://doi.org/10.1023/B:COMH.0000026994.99157.c9.

[5] Chang, E. M., Bidewell, J. W., Huntington, A. D., Daly, J., Johnson, A., Wilson, H., ... \& Lambert, C. E. (2007). A survey of role stress, coping and health in Australian and New Zealand hospital nurses. International journal of nursing studies, 44(8), 1354-1362. https://doi.org/10.1016/j.ijnurstu.2006.06.003.

[6] Folkman, S., Lazarus, R. S., Dunkel-Schetter, C., DeLongis, A., \& Gruen, R. J. (1986). Dynamics of a stressful encounter: cognitive appraisal, coping, and encounter outcomes. Journal of personality and social psychology, 50(5), 992. https://doi.org/10.1037/0022-3514.50.5.992.

[7] Folkman, S., \& Lazarus, R. S. (1988). Coping as a mediator of emotion. Journal of personality and social psychology, 54(3), 466. https://doi.org/10.1037/0022-3514.54.3.466.

[8] Haider, A. H. (2016). Perceived stress among nurses of psychiatric ward patients with and without suicidal behavior (Doctoral dissertation, Bahria University Islamabad Campus). https://doi.org/10.14419/ijans.v6i1.7182.

[9] Johansson, G., Sandahl, C., \& Hasson, D. (2013). Role stress among first-line nurse managers and registered nurses-a comparative study. Journal of Nursing Management, 21(3), 449-458. https://doi.org/10.1111/j.1365-2834.2011.01311.x.

[10] Karimi, L., Cheng, C., Bartram, T., Leggat, S. G., \& Sarkeshik, S. (2015). The effects of emotional intelligence and stress-related presenteeism on nurses' well-being. Asia Pacific Journal of Human Resources, 53(3), 296-310. https://doi.org/10.1111/1744-7941.12049.

[11] Makie, V. V. (2006). Stress and coping strategies amongst registered nurses working in a South African tertiary hospital (Doctoral dissertation, University of the Western Cape).

[12] Rossberg, J. I., Melle, I., Opjordsmoen, S., \& Friis, S. (2008). The relationship between staff members' working conditions and patients' perceptions of the treatment environment. International Journal of Social Psychiatry, 54(5), 437-446. https://doi.org/10.1177/0020764008090689.

[13] Sarma, S., Hawthorne, G., Thakkar, K., Hayes, W., \& Moore, K. H. (2009). The development of an Incontinence Treatment Motivation Questionnaire for patients undergoing pelvic floor physiotherapy in the treatment of stress incontinence. International Urogynecology Journal, 20(9), 10851093. https://doi.org/10.1007/s00192-009-0907-9.

[14] Susilo, A., Rumende, C. M., Pitoyo, C. W., Santoso, W.D., Yulianti, Herikurniaawan, H., \& Chen, L. K. (2020), Coronavirus Disease 2019: Tinjauan Literature Terkini. Jurnal Penyakit Dalam Indonesia. 7 (1), 45- 67. https://doi.org/10.7454/jpdi.v7i1.415. 